\title{
Thoracic ectopia cordis
}

\author{
Jimmy Shad, ${ }^{1}$ Keshav Budhwani, ${ }^{2}$ Rakesh Biswas ${ }^{3}$ \\ ${ }^{1}$ General Surgery Department, People's College of Medical Sciences and Research Centre Bhopal, Bhopal, India; \\ 2Paediatric Surgery Department, G.M.C and Associated Hospital, Bhopal, India; \\ ${ }^{3}$ Medicine Department, People's College of Medical Sciences, Bhopal, India
}

Correspondence to Professor Rakesh Biswas, rakesh7biswas@gmail.com

\section{Summary}

Ectopia cordis is defined as complete or partial displacement of the heart outside the thoracic cavity. It is a rare congenital defect in fusion of the anterior chest wall resulting in extra thoracic location of the heart. Its estimated prevalence is 5.5-7.9 per million live births. The authors had one such case of a 15-h-old full-term male neonate weighing $2.25 \mathrm{~kg}$ with an externally visible, beating heart over the chest wall. The neonate had difficulty in respiration with peripheral cyanosis. Patient died of cardiorespiratory arrest before any surgical intervention could be undertaken inspite of best possible resuscitative measures.

\section{BACKGROUND}

The interesting and curious presentation of the case associated with infrequent occurrence led us to report this case.

\section{CASE PRESENTATION}

A 15-h-old, normal vaginally delivered full-term male neonate, weighing $2.25 \mathrm{~kg}$ was brought with an externally visible, beating heart over the chest wall and difficulty in respiration. There was no history of consanguineous marriage, infection, intake of any teratogens, drugs or exposure to radiation, etc. in antenatal period. The antenatal period was uneventful, though no ultrasonography was done. There was no family history of any such or related congenital abnormality. Examination revealed peripheral cyanosis with heart rate- $150 / \mathrm{min}$, respiratory rate- $76 / \mathrm{min}$ and $\mathrm{SpO}_{2}-88 \%$. The lower half of sternum was bifid, with $5 \mathrm{~cm}$ inter-ridge distance. The heart, lying outside the thoracic cavity was devoid of pericardium (figures 1 and 2; video 1), with its apex pointing anteriorly. Baby also had supraumblical omphalocele with umbilical cord attached at the lower part of the defect.

\section{INVESTIGATIONS}

Investigations: haemoglobin-12 g\%, total leucocyte count8200/cumm, differential leucocyte count: P-48\%, L-42\%, E-4\%, M-2\%, B- $0 \%$. Platelet count-2.3 lakhs/cumm. Blood group-B+ve. Serum bilirubin: T-1.1 mg \%, D-0.4 mg \%, I-0.7 $\mathrm{mg} \%$. Serum Na-146 mmol/1, serum potassium-3 mmol/1.

X-ray chest showed crowding of ribs with bifid lower sternum. Echocardiography showed ventricular septal and pericardial defects.

\section{DIFFERENTIAL DIAGNOSIS}

- Pentalogy of Cantrell.

- Amniotic band syndrome.

- Cyllosomas.

\section{TREATMENT}

Patient was kept in temperature regulated $\left(35^{\circ} \mathrm{C}\right)$ incubator in propped up posture. Initial management included covering of the heart and omphalocele with sterile-saline soaked dressing, systemic antibiotics and supportive treatment. The neonate had progressive respiratory distress, hence intubated, and shifted on mechanical ventilation. Inotropic drugs infusion was started to support the heart and maintain systemic blood pressure. Despite treatment, the child remained hypotensive with deteriorating oxygen saturation levels and blood gas analysis showing progressive acidemia and dyselectrolytemia. Efforts to correct acidosis and electrolyte imbalance were made, but the neonate did not improve and had cardiorespiratory arrest before any surgical intervention could be undertaken.

Video 1 Video shows externally visible beating heart lacking any skin or pericardial covering along with chest wall defect, omphalocele, inferior insertion of umbilical cord.

\section{OUTCOME AND FOLLOW-UP}

The neonate succumbed before any surgical intervention.

\section{DISCUSSION}

Ectopia cordis (EC) was first observed 5000 years ago ${ }^{1}$ Haller first described the term EC in 1706. EC is defined as complete or partial displacement of the heart outside the thoracic cavity. It is a rare congenital defect in fusion of the anterior chest wall resulting in extra thoracic location of the heart. Its prevalence has been estimated to be 5.5-7.9 per million live births. ${ }^{2} 3$ It is generally a sporadic malformation, with reports, linking it to chromosomal abnormalities like trisomy $18,{ }^{4} 5$ Turner syndrome and $46, \mathrm{XX}, 17 q+{ }^{6}$ In our case, the child appeared to have long philtrum and low implant of the ears but on thorough clinical examination no definitive association with any syndrome could be documented and karyotyping to establish any genetic associations could not be done.

Depending upon the location of the heart, it can be classified into five types: cervical ( $5 \%$ ), cervicothoracic and thoracic (65\%), thoracoabdominal (20\%) and abdominal (10\%). ${ }^{7}$ The combination of thoracoabdominal EC, lower sternal defect, anterior diaphragmatic hernia, midline supraumblical defect 


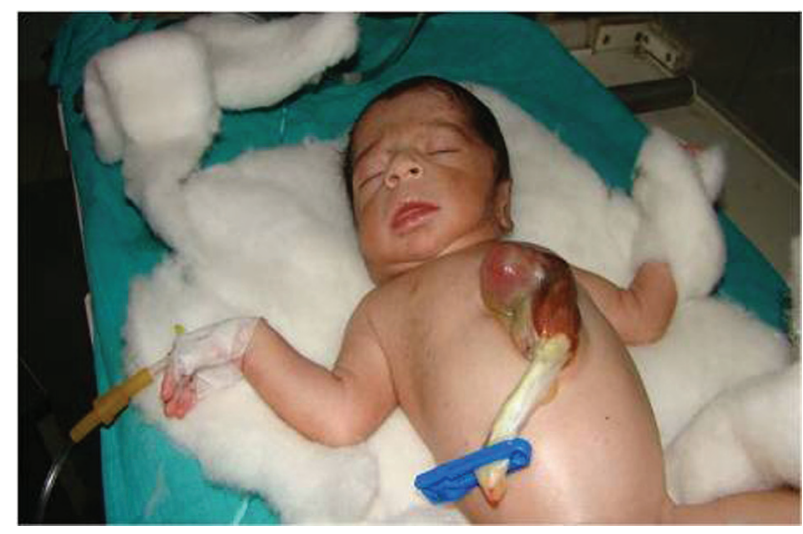

Figure 1 Patient with externally visible heart, no skin or pericardial covering is present over the heart, omphalocele present inferiorly to ectopic heart with umbilical cord inserted at the inferior end of abdominal wall defect.

along with pericardial and intracardiac defects constitute the Pentology of Cantrell. ${ }^{89}$ The thoracic variety, as the present case was, has been reported to have worst prognosis with $<5 \%$ surviving beyond the first month of life. ${ }^{10}$

EC can be diagnosed by routine prenatal ultrasonography as early as in 10-12 weeks of pregnancy. ${ }^{11} 12$ Of those not diagnosed antenataly, most result in stillbirth or die shortly after birth due to their frequent association with intrinsic cardiac and other congenital defects. ${ }^{12} 13$

The development of the ventral body wall begins by eighth day of embryonic life with differentiation and proliferation of mesoderm followed by its lateral migration. The heart originally develops in a cephalic location and reaches its definitive position by the lateral folding and ventral flexing of the embryo at about 16th-17th day. Midline fusion and formation of the thoracic and abdominal cavities is complete by the 9th embryonic week. ${ }^{14} 15$ Complete or incomplete failure of midline fusion at this stage result in disorders varying from isolated EC to complete ventral evisceration. Genesis of EC has not been fully explained, although several theories have been offered. ${ }^{16}$ Popular theories are early rupture of the chorion and/or yolk sac, and amniotic band syndrome. ${ }^{17-19}$

The amnion rupture theory states that during early embryonic development, the amnion surrounding the embryo ruptures, and stringy, sticky, fibrous bands of amnion becomes 'entangled' with the forming embryo, and causes a disruption in the developing parts of the fetus which may lead to various deformities like EC, midline sternal cleft, frontonasal dysgenesis, a midfacial cleft, limb deformities etc. The spectrum of defect corresponds to the timing of its rupture. The findings in the literature suggest that its rupture in the third week of gestation causes an arrest of cardiac descent which may be the cause of such defects. EC with amniotic bands appears to have aetiology distinct from isolated EC. This suggests several different aetiologies for EC. ${ }^{17} 18$ EC has also been attributed to intrauterine drug exposure in animal models. ${ }^{20} 21$

Cyllosomas, another name for limb-body wall complex is defined as anomaly consisting of two of the following three fetal anomalies: a) thoraco-abdominoschisis (opening extends from the chest through the abdomen) or

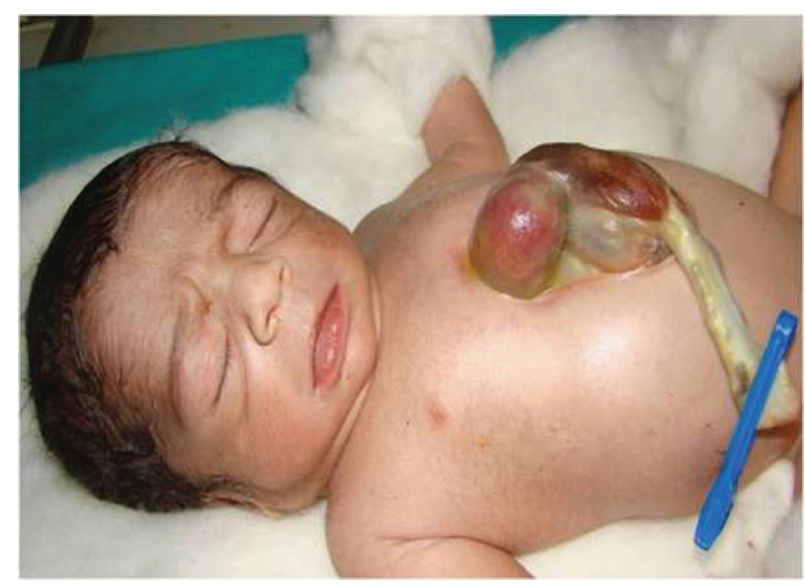

Figure 2 Lateral aspect of the patient.

abdominoschisis (opening starts at a lower point and only extends through the abdomen), b) limb defects, c) craniofacial defects- cleft lip/palate, encephalocele, exencephaly, etc. and others. ${ }^{22}$

Newborns with this complex and life threatening deformity require intensive care right from birth. They require immediate resuscitation and coverage to the exposed heart and viscera with saline-soaked gauze pads wrapping to prevent desiccation and heat loss. For this, Harrison et al have reported use of adherent plastic drapes also. ${ }^{23}$ Thoracic EC presents a formidable surgical challenge. In recent reviews of the literature the reported survival of this variety after birth averages $36 \mathrm{~h}$; intracardiac defects were associated in $80.2 \%$ of the cases, and all unoperated patients died. ${ }^{24}$ Besides intrinsic cardiac defects, the increased morbidity in these patients may be attributed to the abnormal course, length and positioning of great vessels of the heart making them prone to kinking and further compromising circulation, as also must have been in our case. During surgical closure, in most of the cases the thoracic cavity is small with little mediastinal space for the heart. Attempts to close the chest wall often result in intolerable haemodynamic embarrassment secondary to kinking of the great vessels possibly due to their long length and abnormal course, or compression of the heart. Therefore, a staged repair is often necessary. The strategy for repair is divided in two stages: (1) urgent soft tissue coverage and haemodynamic palliation if necessary; and (2) intracardiac repair with concomitant chest wall reconstruction and reduction of the heart into the thoracic cavity.

The overall surgical objective of EC (all variety) management includes: 1) closure of the chest wall defect (either by doing primary chest wall closures or by using bone/cartilage as tissue graft or artificial prosthesis like acrylic plaques, marlex mesh), 2) closure of the sternal defect, 3) repair of the associated omphalocele, 4) placement of the heart into the thorax, 5) repair of the intracardiac defect.

The first attempted repair of EC was performed in 1925 by Cutler and Wilens. ${ }^{25}$ Koop in 1975 achieved the first successful repair of thoracic EC in two stages. ${ }^{26}$ Amato et al reported successful single stage repair of thoracic EC in 1995. ${ }^{27}$ Cristofer Wall operated by Koop in August-1975 is the oldest live pt of EC. Other surviving operated cases which could be traced on literature search are: 
- Aytag and Sayam successfully operated partial EC in $1976^{28}$

- Dobell et al, reported two stage correction ${ }^{16}$

- Kim KA et al, - Los Angeles - 1996, did two - stage operation. ${ }^{29}$

- Morales et al - reported successful 2-stage repair of EC on female baby. ${ }^{30}$

- Khaled et al from France reported successful single stage repair in $2003 .^{3}$

- Gonçalves et al at Brazil reported successful repair of uncomplicated EC in June 2007.31

Hence it may be concluded that EC is a lethal anomaly requiring prompt medical and surgical interventions. Surgery on these patients with life-threatening complex intracardiac anomalies, owes the only chance of survival, which should still be attempted despite heretofore poor outcomes. Although the available literature is scant, but with the advance in all aspects of medicine, the number of patients who undergo successful surgical repair and survive should steadily increase, with our combined efforts to understand and formulate treating protocol of this extremely rare anomaly.

\section{Learning points}

- Success of repair is dictated by the presence and severity of the intrinsic cardiac defects and associated congenital anomalies, rather than the type of surgical approach.

- Surgical technique is evolving, and surgical options should be considered in all cases, taking comorbidities into account.

- Antenatal ultrasonography plays an important role in detecting such anomalies which may be important for planning its further management.

\section{Competing interests None.}

Patient consent Obtained.

\section{REFERENCES}

1. Taussig HB. World survey of the common cardiac malformations: developmental error or genetic variant? Am J Cardiol 1982:50:544-59.

2. Khoury MJ, Cordero JF, Rasmussen S. Ectopia cordis, midline defects and chromosome abnormalities: an epidemiologic perspective. Am J Med Genet 1988:30:811-7.

3. Khaled S, Olivier G, Dominique M, et al. Ectopia cordis. A successful single stage thoracoabdominal repair. Int Cardiovasc Thorac Surg 2003;2:611-3.

4. King CR. Ectopia cordis and chromosome errors. Pediatrics 1980;66:328.

5. Soper SP, Roe LR, Hoyme HE, et al. Trisomy 18 with ectopia cordis, omphalocele, and ventricular septal defect: case report. Pediatr Pathol 1986:5:481-3.
6. Say B, Wilsey CE. Chromosome aberration in ectopia cordis $(46, X X, 17 q+) . A m$ Heart J 1978:95:274-5.

7. Anderson RH, Shinebourne EA, Macartney FJ, et al. Abnormal positions and relationships of the heart. Anderson $\mathrm{RH}$, Shinebourne EA. Paediatric Cardiology. London: Churchill Livingstone 1987:1057-72.

8. Fonkalsrud EW. Chest wall abnormalities. Bove AE, Geha AS, Hammond GL, Laks H, Naunheim KS, eds. Glenn's Thoracic and Cardiovascular Surgery. East Norwalk, Connecticut: Appleton and Lange 1991:507-16.

9. Greenberg BM, Becker JM, Pletcher BA. Congenital bifid sternum: repair in early infancy and literature review. Plast Reconstr Surg 1991;88:886-9.

10. Shamberger RC, Welch KJ. Sternal defects. Pediatr Surg 1990;5:156-64

11. Cuillier F, Avignon MS, Avignon A. Pentalogy of Cantrell, 11 weeks. Pentalogy of Cantrell, 11 weeks (C) Cuillier. [cited on 2006 Feb 20]. http://www.thefetus.net.(accessed September 2012).

12. Repondek-Liberska M, Janiak K, Wloch A. Fetal echocardiography in ectopia cordis. Pediatr Cardiol 2000:21:249-52.

13. Meyer WJ, Gauthier DW, Torres W, et al. Heart, cordis ectopia. Ectopia cordis (C) Meyer. [cited on 1991 Nov 1]. http://www.thefetus.net (accessed September 2012).

14. Cantrell JR, Haller JA, Ravitch MM. A syndrome of congenital defects involving the abdominal wall, sternum, diaphragm, pericardium, and heart. Surg Gynecol Obstet 1958;107:602-14

15. Kanagasuntheram $\mathbf{R}$, Verzin JA. Ectopia cordis in man. Thorax 1962:17:159-67.

16. Dobell AR, Williams HB, Long RW. Staged repair of ectopia cordis. J Pediatr Surg 1982:17:353-8.

17. Kaplan LC, Matsuoka R, Gilbert EF, et al. Ectopia cordis and cleft sternum: evidence for mechanical teratogenesis following rupture of the chorion or yolk sac. Am J Med Genet 1985:21:187-202.

18. Van Allen MI, Myhre S. Ectopia cordis thoracalis with craniofacial defects resulting from early amnion rupture. Teratology 1985;32:19-24.

19. Bieber FR, Mostoufi-zadeh M, Birnholz JC, et al. Amniotic band sequence associated with ectopia cordis in one twin. J Pediatr 1984;105:817-9.

20. Jaffee OC, Jaffee AL. Ectopia cordis in the chick embryo heart: an experimental study. Teratology 1990;41:737-42.

21. Russo R, D'Armiento M, Angrisani $P$, et al. Limb body wall complex: a critical review and a nosological proposal. Am J Med Genet 1993;47:893-900.

22. Morello M, Quaini E, Nenov G, et al. Extrathoracic ectopia cordis. Case report. J Cardiovasc Surg (Torino) 1994;35:511-5.

23. Harrison MR, Filly RA, Stanger $P$, et al. Prenatal diagnosis and management of omphalocele and ectopia cordis. J Pediatr Surg 1982;17:64-6.

24. Barrow MV, Willis LS. Ectopia cordis (ectocardia) and gastroschisis induced in rats by maternal administration of the lathyrogen, betaaminopropionitrile (BAPN). Am Heart J 1972;83:518-26.

25. Cutler GD, Wilens G: Ectopia cordis: report of a case. Am J Dis Child 1925; $\mathbf{3 0}: 76$.

26. Saxena AK. Pectus excavatum, pectus carinatum and other forms of thoracic deformities. J Indian Assoc Pediatr Surg 2005;10:147-57.

27. Amato JJ, Zelen J, Talwalkar NG. Single-stage repair of thoracic ectopia cordis. Ann Thorac Surg 1995; 59:518-20.

28. Aytag A, Sayam A. Successful surgical repair of congenital total cleft sternum with partial ectopia cordis. Thorax 1976:31:466-9.

29. Kim KA, Vincent WR, Muenchow SK, et al. Successful repair of ectopia cordis using alloplastic materials. Ann Plast Surg 1997:38:518-22.

30. Morales JM, Patela SG, Duff JA, et al. Ectopia cordis and other midline defects. Ann Thorac Surg 2000;70:111-4.

31. Gonçalves FD, Novaes FR, Maia MA et al. Thoracic ectopia cordis with anatomically normal heart. Rev Bras Cir Cardiovasc 2007;22:no.2 São José does Rio Preto April/June. http://dx.doi.org/10.1590/S010276382007000200015 (accessed September 2012). 


\section{BMJ Case Reports}

This pdf has been created automatically from the final edited text and images.

Copyright 2012 BMJ Publishing Group. All rights reserved. For permission to reuse any of this content visit http://group.bmj.com/group/rights-licensing/permissions.

BMJ Case Report Fellows may re-use this article for personal use and teaching without any further permission.

Please cite this article as follows (you will need to access the article online to obtain the date of publication).

Shad J, Budhwani K, Biswas R. Thoracic ectopia cordis. BMJ Case Reports 2012;10.1136/bcr.11.2011.5241, Published XXX

Become a Fellow of BMJ Case Reports today and you can:

- Submit as many cases as you like

- Enjoy fast sympathetic peer review and rapid publication of accepted articles

- Access all the published articles

- Re-use any of the published material for personal use and teaching without further permission

For information on Institutional Fellowships contact consortiasales@bmjgroup.com

Visit casereports.bmj.com for more articles like this and to become a Fellow

Keep up to date with all published cases by signing up for an alert (all we need is your email address) http://casereports.bmj.com/cgi/alerts/etoc 